\title{
Effects of foliar application of silicon on uptake and translocation of arsenite and DMA in rice (Oryza sativa)
}

\author{
W.-J. Liu, Y. Sun \& Q.-L. Zhao \\ College of Resources and Environmental Science, Hebei Agricultural University, Baoding, P.R. China
}

\begin{abstract}
A hydroponic experiment was conducted to explore the effects of foliar application of silicon on the uptake and translocation of As(III) and DMA in rice. The result showed that the ratio of foliar application of Si concentration and the As concentration in the solution at 100:1 decreased significantly arsenic concentrations in the phloem sap and the rice shoots. However, when DMA supplied, Si/As ratio at 200:1 increased significantly arsenic and silicon concentrations in rice phloem $(\mathrm{P}<0.05)$. In addition, there was a positive correlation between arsenic concentrations and silicon concentration in rice phloem $(\mathrm{R}=0.856, \mathrm{P}<0.01, \mathrm{n}=12)$. Regardless of whether As(III) or DMA was supplied to rice, foliar application of low concentration of silicon (Si/As at 100:1) could decrease arsenic concentration and translocation in rice seedlings.
\end{abstract}

\section{INTRODUCTION}

Arsenite (As(III)) is the predominant species of As in soil solution from flooded paddy fields. As(III) as $\mathrm{H}_{3} \mathrm{AsO}_{3}^{0}$ is an analogue of silicic acid $\left(\mathrm{H}_{4} \mathrm{SiO}_{4}^{0}\right)$ $(\mathrm{pH}<8)$ and can be taken up by rice roots through the silicic acid transport system (Ma et al., 2008). The similar situation had happened to Di-methylated arsenic (DMA) into rice roots (Li et al., 2009). However, application $\mathrm{Si}$ in the submerged soil would increase As(III) and DMA mobility (Lee et al., 2014; Liu et al., 2014). Therefore, we want to know that the impact of foliar application Si with the different concentrations on the uptake and translocation of As(III) and DMA in rice.

\section{METHODS/EXPERIMENTAL}

\subsection{Plant growth}

Rice (Oryza sativa L. cv. Italica Carolina, the Japonica type, an early flowering cultivar) seeds were sterilized in $30 \% \mathrm{H}_{2} \mathrm{O}_{2}$ solution for $15 \mathrm{~min}$ followed by thorough washing with de-ionized water. The seeds were germinated in moist quartz sand. After 3 weeks, rice seedlings were transplanted to $500 \mathrm{~mL}$ PVC pots $(7.5 \mathrm{~cm}$ diameter and height $14 \mathrm{~cm}$, one plant per pot) containing half-strength Kimura $\mathrm{B}$ solution. The composition of the nutrient solution was $0.091 \mathrm{mM} \mathrm{KNO}_{3}, 0.183 \mathrm{mM} \mathrm{Ca}\left(\mathrm{NO}_{3}\right)_{2}$, $0.274 \mathrm{mM} \mathrm{MgSO}_{4}, 0.091 \mathrm{mM} \mathrm{KH} \mathrm{KO}_{4}, 0.183 \mathrm{mM}$ $\left(\mathrm{NH}_{4}\right)_{2} \mathrm{SO}_{4}, 0.5 \mu \mathrm{M} \mathrm{MnCl}, 3 \mu \mathrm{M} \mathrm{H}_{3} \mathrm{BO}_{3}, 0.1 \mu \mathrm{M}$ $\left(\mathrm{NH}_{4}\right)_{6} \mathrm{Mo}_{7} \mathrm{O}_{24}, 0.4 \mu \mathrm{M} \mathrm{ZnSO}_{4}, 0.2 \mu \mathrm{M} \mathrm{CuSO}_{4}$, $20 \mu \mathrm{M} \mathrm{NaFe}$ (III)-EDTA (pH adjusted to 5.5 with $\mathrm{KOH}$ ). Nutrient solutions were renewed once every $3 \mathrm{~d}$. The growth conditions were $14 \mathrm{~h}$ photoperiod with a light intensity of $280 \mu \mathrm{mol} \mathrm{m}^{-2} \mathrm{~s}^{-1}$ and day/night temperatures were maintained at $28 / 25^{\circ} \mathrm{C}$.

\subsection{Experiment treatments}

Rice plants at heading stage were exposed to the halfstrength Kimura B nutrient solution containing $10 \mu \mathrm{M}$ As(III) or $10 \mu \mathrm{M}$ DMA. Different levels of 0 (CK), $1000\left(\mathrm{D}_{\mathrm{Si}}\right), 2000\left(\mathrm{G}_{\mathrm{Si}}\right) \mu \mathrm{M}$ Si as silicic acid were sprayed on the rice shoots at 10:10 am every day and the exposure of As and Si would last for $72 \mathrm{~h}$. Thus, the ratios of $\mathrm{Si}$ to $\mathrm{As}(\mathrm{Si} / \mathrm{As})$ would be 100:1 and 200:1. Silicic acid was prepared by passing potassium silicate through a cation-exchange resin (Amberlite IR-120B, $\mathrm{H}^{+}$form).

After $72 \mathrm{~h}$ of As and Si exposure, phloem sap, rice shoot and rice root were collected for total arsenic detection.

\subsection{Total As analysis}

Shoots $(0.2 \mathrm{~g} \mathrm{FW})$ and roots (approx. $0.1 \mathrm{~g} \mathrm{FW}$ ) samples were digested in $5 \mathrm{~mL} \mathrm{HNO}_{3}$ (Liu et al., 2004b). Reagent blank and certified reference material (GBW07603 from the National Research Center for Standard Materials in China) were included to verify the accuracy and precision of the digestion procedure and subsequent analysis. Total As concentrations in the samples (phloem sap, rice shoot and root) were determined atomic by fluorescence spectrometry (AFS9600, Beijing Haiguang Instrument Co., Beijing, China).

\subsection{Statistical analysis}

The significance of treatment effects was determined by analysis of variance (ANOVA) using statistical package SPSS 17.0 for windows. Tukey's multiple comparison tests were carried out according to the LSD (least significance difference) values. 


\section{RESULTS AND DISCUSSION}

\subsection{Arsenic in phloem sap influenced by foliar application of $\mathrm{Si}$}

For As(III) treatment, the foliar application of Si concentration at $1000 \mu \mathrm{M}(\mathrm{Si} / \mathrm{As}$ ratio at 100:1) decreased significantly As levels in phloem sap $(\mathrm{P}<0.05)$ (Fig. 1). However, when DMA applied in nutrient solution, the foliar application of Si increased As concentrations in phloem sap significantly. There was a positive correlation between As concentrations and silicon levels in rice phloem only for rice exposed to medium with DMA $(\mathrm{R}=0.856, \mathrm{P}<0.01, \mathrm{n}=12)$.

\subsection{Arsenic concentrations in rice root and shoot influenced by Si foliar application}

When As(III) supplied in nutrient solution, Si foliar application did not influence As accumulation in root while $1 \mathrm{mM} \mathrm{Si}$ addition decreased As levels in root significantly (Table 1). For DMA treatment, both $1 \mathrm{mM}$ and $2 \mathrm{mM}$ silicic acid foliar application reduced arsenic accumulation in rice roots and shoots. It indicated that foliar application $\mathrm{Si}$ could mediate As transported into rice grain under DMA in the growth medium and foliar Si application would be better to control As accumulation in rice plants for DMA treatment than that of As(III) supply.

\subsection{Arsenic translocation affected by Si foliar application}

As translocation factor ranged from $\sim 0.03-0.05$ for As(III) treatment while from $\sim 0.17-0.19$ for DMA treatment (Fig. 2), which meant DMA had higher efficiency to transport from root to shoot than that of

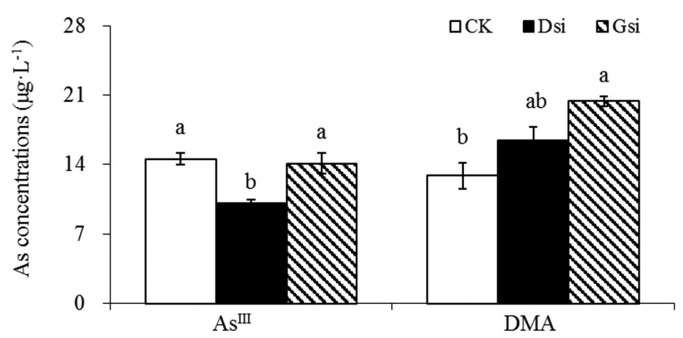

Figure 1. As concentration in rice phloem sap under the different Si concentration.

Table 1. As concentration in rice roots and shoots under the different treatments.

\begin{tabular}{|c|c|c|c|}
\hline & CK & Dsi & Gsi \\
\hline & \multicolumn{3}{|l|}{ Root-As (mg/kg) } \\
\hline As(III) & $216.3 \pm 2.03 b$ & $304.2 \pm 8.53 \mathrm{a}$ & $202.0 \pm 9.08 b$ \\
\hline \multirow[t]{2}{*}{ DMA } & $24.4 \pm 0.41 \mathrm{a}$ & $19.5 \pm 1.25 b$ & $16.0 \pm 1.21 \mathrm{c}$ \\
\hline & \multicolumn{3}{|c|}{ Shoot-As (mg/kg) } \\
\hline As(III) & $10.5 \pm 0.07 \mathrm{a}$ & $9.01 \pm 0.19 b$ & $10.6 \pm 0.07 \mathrm{a}$ \\
\hline DMA & $4.96 \pm 0.34 \mathrm{a}$ & $3.23 \pm 0.39 b$ & $2.99 \pm 0.25 b$ \\
\hline
\end{tabular}

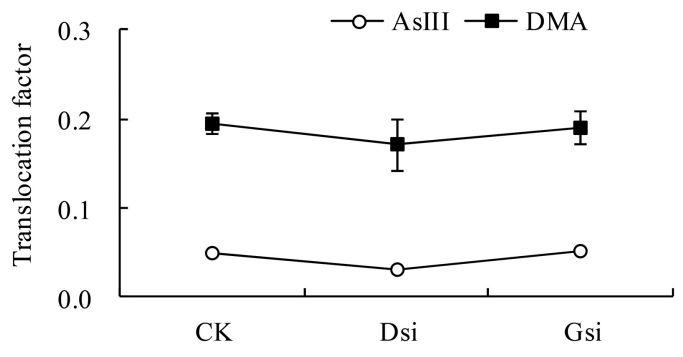

Figure 2. The translocation factor of arsenic in rice root to shoot under different Si treatments.

As(III). When $1 \mathrm{mM}$ Si was sprayed on the rice shoots, the ratios of arsenic concentrations from roots to shoots were lowest regardless of whether As(III) or DMA in the growth medium.

\section{CONCLUSIONS}

The ratio of foliar application of Si concentration to As concentration in the solution at 100:1 decreased significantly As levels in phloem sap and rice shoots for arsenite treatment. When DMA supplied, $\mathrm{Si} / \mathrm{As}$ ratio at 200:1 increased significantly arsenic and silicon concentrations in rice phloem $(\mathrm{P}<0.05)$. In addition, there was a positive correlation between As concentrations and silicon levels in rice phloem $(\mathrm{R}=0.856$, $\mathrm{P}<0.01, \mathrm{n}=12$ ). Whether As(III) or DMA was supplied to rice, foliar application of low concentration of silicon ( $\mathrm{Si} /$ As at 100:1) decrease arsenic concentration and translocation in rice.

\section{ACKNOWLEDGEMENTS}

This research was supported by the Natural Science Foundation of China (41471398). We thank Professor Fangjie Zhao of Agricultural University of Nanjing and Rothamsted Research for providing rice seeds. We also sincerely thank Dr. Ben Simon for improving this manuscript in language.

\section{REFERENCES}

Lee, C.H., Huang, H.H., Syu, C.H., Lin, T.H. \& Lee, D.Y. 2014. Increase of As release and phytotoxicity to rice seedlings in As-contaminated paddy soils by Si fertilizer application. J. Hazard. Mater. 276: 253-261.

Li, R.Y., Ago, Y., Liu, W.J., Mitani, N., Feldmann, J., McGrath, S.P., Ma, J.F. \& Zhao, F.J. 2009. The rice aquaporin Lsi1 mediates uptake of methylated arsenic species. Plant Physiol. 150(4): 2071-2080.

Liu, W.J., McGrath, S.P. \& Zhao, F.J., 2014. Silicon has opposite effects on the accumulation of inorganic and methylated arsenic species in rice. Plant Soil 376(1-2): 423-431.

Ma, J.F., Yamaji, N., Mitani, N., Xu, X.Y., Su, Y.H., McGrath, S.P. \& Zhao, F.J. 2008. Transporters of arsenite in rice and their role in arsenic accumulation in rice grain. Proc. Natl. Acad. Sci. U S A 105(29): 9931-9935. 